\title{
Chiral amplification of chiral porphyrin derivatives by templated heteroaggregation
}

Donato Monti, ${ }^{* a}$ Mariano Venanzi $i{ }^{\text {a }}$ Manuela Stefanelli, ${ }^{\text {a }}$ Alessandro Sorrenti, ${ }^{\mathrm{b}}$ Giovanna Mancini, ${ }^{\mathrm{b}}$ Corrado Di Natale, ${ }^{\mathrm{c}}$ and Roberto Paolesse ${ }^{\mathrm{a}, \mathrm{c}}$

\section{Supplementary Material}

\section{Experimental}

General. UV-Visible spectra were performed on a Perkin Elmer $\lambda 18$ Spectrophotometer. CD spectra have been performed on a JASCO J-600, equipped with a thermostated cell holder, and purged with ultra-pure nitrogen gas.

Solvents used were of highest degree of purity and used as received. Chemicals were of the highest grade available, and used without further purification. Silica gel 60 (70230 mesh) was used for column chromatography. Solvents employed in the spectroscopic studies are of spectroscopic grade and used as received. Milli-Q, Millipore, previously doubly distilled water, was used for the preparation of porphyrin aqueous solutions. Porphyrin stock solutions were freshly prepared, stored in the dark, and used within a week.

Kinetic studies: Kinetic experiments were performed on a Perkin Elmer $\lambda 18$ Spectrophotometer equipped with a termostating apparatus $\left(25 \pm 0.5^{\circ} \mathrm{C}\right)$, by measuring the UV-Visible spectroscopic changes of porphyrins with time. Porphyrin aqueous solutions, suited for kinetic studies, were prepared as follows. Proper aliquots, of a millimolar stock solution in ethanol $(15 \div 150 \mu \mathrm{L})$, where added to a proper amount of ethanol (1.0 mL final volume) in an $8 \mathrm{~mL}$ glass vial. To this solution $3.0 \mathrm{~mL}$ of water were then added and the resulting solution vigorously shaken. A ca $3 \mathrm{~mL}$ portion was then transferred in a quartz couvette and the relative UV-Visible spectra acquired. This procedure ensures a 75:25 $\mathrm{H}_{2} \mathrm{O} / \mathrm{EtOH}$ (v:v) final solvent composition, with a final $\mathbf{1 H}_{\mathbf{2}}$ concentration spanning in the range of 0.75 to $1.5 \times 10^{-5} \mathrm{M}$. 
Templated aggregation studies were carried out in a similar way, by adding $3 \mathrm{ml}$ of aqueous solution of $\mathbf{2} \mathbf{H}_{2}$ aggregates to a $1 \mathrm{~mL}$ of $\mathbf{1} \mathbf{H}_{\mathbf{2}}$ ethanol solution.

Values of $k$ were obtained by analysing the absorbance (extinction) $v s$ time data points by a biexponential kinetic treatment, proposed by Mallamace et al., for related case of aggregation of porphyrin derivatives (F. Mallamace, L. Monsú Scolaro, A. Romeo, N. Micali, Phys. Rev. Lett. 1999, 82, 3480-3483). The equation used is as follows:

$$
E(t)=E_{0}+E_{l} \exp \left(-k_{1} t\right)+E_{2} \exp \left(-k_{2} t\right)
$$

where $E_{i}$ are the calculated extinction values. The term extinction is of more appropriate use than Absorbance, due to the presence of the contribution of scatter in the optical density of the solution (see: N. Micali, F. Mallamace, M. Castriciano, A. Romeo, and L. Monsú Scolaro, Anal. Chem. 2001, 73, 4958-4963). The kinetic constants, $k_{1}$ and $k_{2}$ where obtained by nonlinear least-squares regression fit (Kaleidagraph ${ }^{\circledR}$ program, Synergy Software, 2003) over hundreds of experimental data points. The kinetic experiments were run in duplicate, and the results were in good agreement within the experimental error $( \pm 5 \%)$. Values obtained at different wavelength (e.g. $446 \mathrm{~nm}$ ) were similar, within experimental errors.

A different protocol, entailing the simple addition of $\mathbf{1 H}_{\mathbf{2}}$ stock solution to a preformed $\mathrm{H}_{2} \mathrm{O} / \mathrm{EtOH}$ mixture, gave similar, although less reproducible results. Kinetic experiments have been also carried out by CD spectroscopy, obtaining experimental data in nice agreement to those obtained by UV-Visible techniques. A typical plot, showing the relative spectral variation upon aggregation, is reported in Figure S1.

Deaggregation experiments were carried out by adding a proper aliquot of an ethanolic, concentrated $\mathbf{3} \mathbf{H}_{2}$ stock solution $(5-15 \mu \mathrm{L})$ to a solution of, already formed, templated aggregates of $\mathbf{1} \mathbf{H}_{\mathbf{2}}$ on $\mathbf{2} \mathbf{H}_{\mathbf{2}}$. The evolution of the systems with time was nicely followed by $\mathrm{CD}$ spectroscopy. The corresponding $\mathrm{CD}$ spectral variations are reported in Figure $\mathrm{S} 2$. 
CD spectra of templated aggregates have also been recorded at different temperature. The CD spectral pattern profiles, in terms of intensities and $\lambda$ maxima show little variations on going from $25^{\circ} \mathrm{C}$ to $75^{\circ} \mathrm{C}$, even after prolonged standing ( 3 hours). Results have been graphically reported in Figure S3.

Deposition studies of $\mathbf{1 H}_{2}$ on glass surfaces. Microscope glass slides, with silanised hydrophobic surface, were used as substrate. Dipping the slides into an aqueous solution of $\mathbf{1 H}_{2}\left(2 \times 10^{-6} \div 7.5 \times 10^{-5} \mathrm{M} ; \mathrm{H}_{2} \mathrm{O} / \mathrm{EtOH} 75: 25\right.$, v:v) resulted in the deposition of porphyrin aggregates, as evidenced by the typical yellow coloration of the glass surfaces. Complete deposition (UV-vis check of the Soret bands) is achieved in 12-24 hrs, depending on the concentration of the starting aqueous solutions. The extent of deposition depends on the initial concentration of the solution. A plot of absorption values $v s$ initial porphyrin concentration shows a linear dependence up to ca $2 \times 10^{-5}$ M, likely indicating an uniform and regular deposition of layers. The corresponding plot of optical density $v s$ initial porphyrin bulk concentration is reported in Figure S3. CD spectroscopy studies on these layered samples evidenced the presence of chiroptical features of the layered material, indicating that the supramolecular chirality of the aggregates is retained during the deposition step. This is graphically reported in the Inset of Figure S4.

Resonance light scattering experiments: RLS experiments have been performed on a Spex Fluorolog Fluorimeter. Spectra have been acquired, at $25 \pm 0.5^{\circ} \mathrm{C}$, in a "synchronous scan" mode, in which the emission and excitation monochromators are pre-set to identical wavelengths. Solutions have been prepared by following the protocol used in the kinetic experiments.

Preparation of porphyrin derivatives. All the reactions were carried out in an inert atmosphere. The protocol followed for the synthesis of $\mathbf{1 H}_{\mathbf{2}}$ is outlined in Scheme S1. $\mathrm{N}$-[5-(4-aminophenyl)-10,15,20-triphenylporphyrinyl]-L-prolin( $N$-methyl)amide, $\mathbf{4} \mathbf{H}_{\mathbf{2}}$. To a stirred solution of $0.4 \mathrm{~g}$ of 5-(4-aminophenyl)-10,15,20-triphenylporphyrin $(0.635 \mathrm{mmol})$ in $50 \mathrm{~mL}$ of anhydrous THF kept at $0{ }^{\circ} \mathrm{C}, 0.082 \mathrm{~g}$ of N-methyl-Lproline monohydrate $(0.635 \mathrm{mmol}), 0.1 \mathrm{~g}$ of $\mathrm{N}$-methyl-morpholine $(0.80 \mathrm{mmol})$, and $0.086 \mathrm{~g}$ of HOBT $(0.635 \mathrm{mmol})$ were added. The reaction mixture was stirred under a 
nitrogen atmosphere for 1 hour at $0{ }^{\circ} \mathrm{C}$. EDC- $\mathrm{HCl}(0.129 \mathrm{~g}, 0.667 \mathrm{mmol})$ was then added and the reaction mixture was stirred for additional 48 hours at room temperature. After that time a tlc run $\left(\mathrm{CHCl}_{3}-1 \% \mathrm{MeOH}\right)$ showed no further progress of the reaction. The solvent was then removed under reduced pressure and the residue dissolved in $100 \mathrm{~mL}$ of chloroform and extracted with brine $(3 \times 100 \mathrm{~mL})$. The organic layer was dried $\left(\mathrm{Na}_{2} \mathrm{SO}_{4}\right)$ and the solvent evaporated to give a red solid that was applied to a short $\mathrm{SiO}_{2}$ chromatographic column and eluted with a $\mathrm{CHCl}_{3} / \mathrm{CH}_{3} \mathrm{OH}$ 9:1 v/v solvent mixture. The unreacted aminophenylporphyrin derivative was separated. The L-proline-porphyrin conjugate was subsequently separated by eluting with a $\mathrm{CHCl}_{3} / \mathrm{CH}_{3} \mathrm{OH} 9: 1 \mathrm{v} / \mathrm{v}$ solvent mixture. A $0.090 \mathrm{~g}$ crop $(0.120 \mathrm{mmol} ; 18 \%$ yield) of the title porphyrin was recovered after solvent evaporation, and used without further purification in the subsequent reactions.

$\mathrm{UV}-\mathrm{V}$ is $\left(\mathrm{CHCl}_{3}\right): \lambda_{\max }(\log \varepsilon) 419$ (5.1), 514 (3.8), 546 (3.6), 586 (3.5), 645 (3.2). FAB-MS (NBA), $m / e: 741[\mathrm{M}-\mathrm{H}]^{+}$. $N$-[5-(4-aminophenyl)-10,15,20-triphenylporphyrinyl]-L-(N,N-dimethyl)prolininium amide chloride, $\mathbf{1 H}_{2}$. In a $100 \mathrm{~mL}$ two-necked round bottomed flask, $0.06 \mathrm{~g}$ of porphyrin $\mathbf{2} \mathbf{H}_{2}(0.08 \mathrm{mmol})$ were dissolved in $50 \mathrm{~mL}$ of dry DMF. To this solution, stirred under an inert atmosphere, $600 \mathrm{mg}$ of $\mathrm{CH}_{3} \mathrm{I}$ (4 mmol) where added. The reaction mixture was stirred at room temperature for 24 hours. After that time a tlc run $\left(\mathrm{CHCl}_{3}-5 \% \mathrm{CH}_{3} \mathrm{OH}\right)$ showed no further progress of the reaction. Usual workup of the mixture gave, after column chromatography $\left(\mathrm{SiO}_{2}, \mathrm{CHCl}_{3}-5 \% \mathrm{CH}_{3} \mathrm{OH}\right.$ as eluant $)$ gave a red microcrystalline solid. The product was subsequently dissolved in methanol (25 $\mathrm{mL})$ and stirred overnight with a large excess of solid $\mathrm{NaCl}(1 \mathrm{~g})$. The mixture was then filtered and evaporated under reduced pressure. The red solid was then dissolved in the minimum amount of $\mathrm{CH}_{2} \mathrm{Cl}_{2}$, filtered and crystallised by addition of n-pentane obtaining $0.05 \mathrm{~g}(0.065 \mathrm{mmol}, 80 \%$ yield $)$ of $\mathbf{1 H}_{\mathbf{2}}$, as a bright purple crystalline solid. UV-Vis $\left(\mathrm{CHCl}_{3}\right)$ : $\lambda_{\max }(\log \varepsilon) 419$ (5.0), 514 (3.7), 546 (3.6), 586 (3.5), 645 (3.1).

${ }^{1} \mathrm{H}-\mathrm{NMR}\left(\mathrm{CD}_{3} \mathrm{OD}\right), \delta:$ 9.1-8.5 (brs, 8H, pyrrole $\beta$-Hs), 8.2 (m, 10H, Aromatics), 7.8 (m, 9H, Aromatics), $3.9(\mathrm{~m}, 1 \mathrm{H}$, proline $\delta-\mathrm{H}), 3.7(\mathrm{~m}, 1 \mathrm{H}$, proline $\delta-\mathrm{H}), 3.45(\mathrm{~d}, \mathrm{~J}=12$ $\mathrm{Hz}, 6 \mathrm{H}$, proline $\mathrm{NMe}), 2.7(\mathrm{~m}, 2 \mathrm{H}$, proline $\beta-\mathrm{H}), 2.4(\mathrm{~m}, 2 \mathrm{H}$, proline $\gamma-\mathrm{H}),-2.81$ (brs, 2H, pyrrole $\mathrm{NH}) \mathrm{ppm}$.

FAB-MS (NBA), m/e: $756[\mathrm{M}-\mathrm{Cl}]^{+}$. 
Schemes and Figures

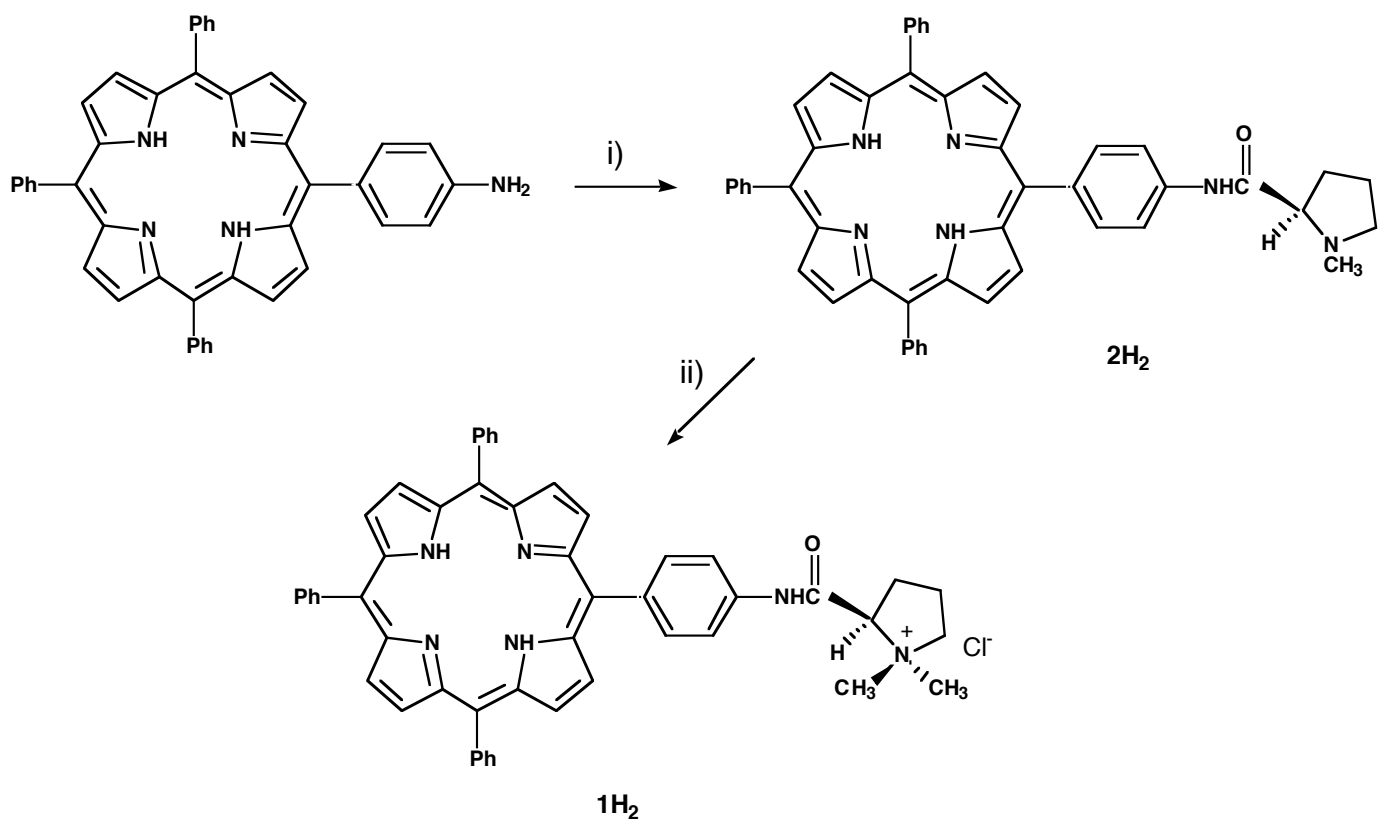

Scheme 1. i) EDC, HOBT, N-methyl morpholine, L-(N-Me)proline, $\mathrm{CHCl}_{3}, 1 \mathrm{~h}$ at $0{ }^{\circ} \mathrm{C}$, then $48 \mathrm{~h}$ at r.t. ii) $\mathrm{CH}_{3} \mathrm{I}$, DMF, r.t. 24 h. $\mathrm{NaCl}$ in $\mathrm{MeOH}$, r.t. overnight.

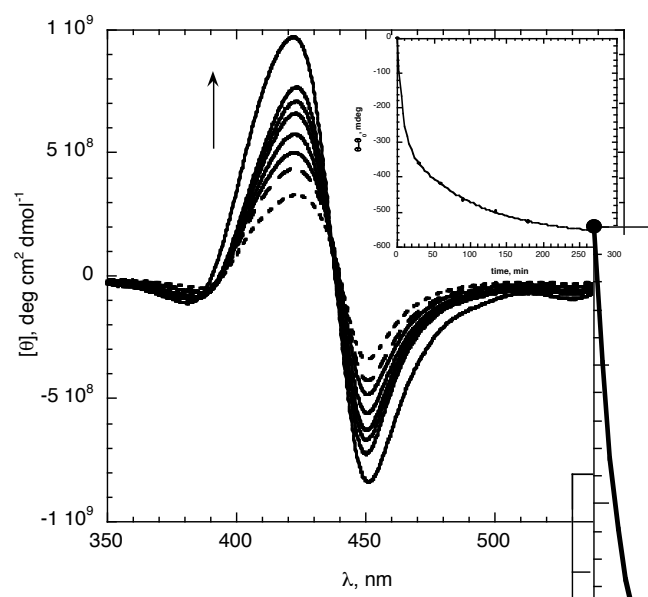

Figure S1. CD spectral changes upon templated aggregation of $\mathbf{1 H}_{\mathbf{2}}\left(7.5 \times 10^{-6} \mathbf{M}\right)$ onto aggregates of $\mathbf{2 H}_{2}\left(1.5 \times 10^{-5} \mathrm{M} ; \mathrm{H}_{2} \mathrm{O} / \mathrm{EtOH} 75 / 25 \mathrm{v}\right.$ :v). Lowermost trace: $\mathrm{t}=0$ min; uppermost trace: $t=250 \mathrm{~min}$. In the inset, the corresponding curve fit is reported, according to biexponential decay. 


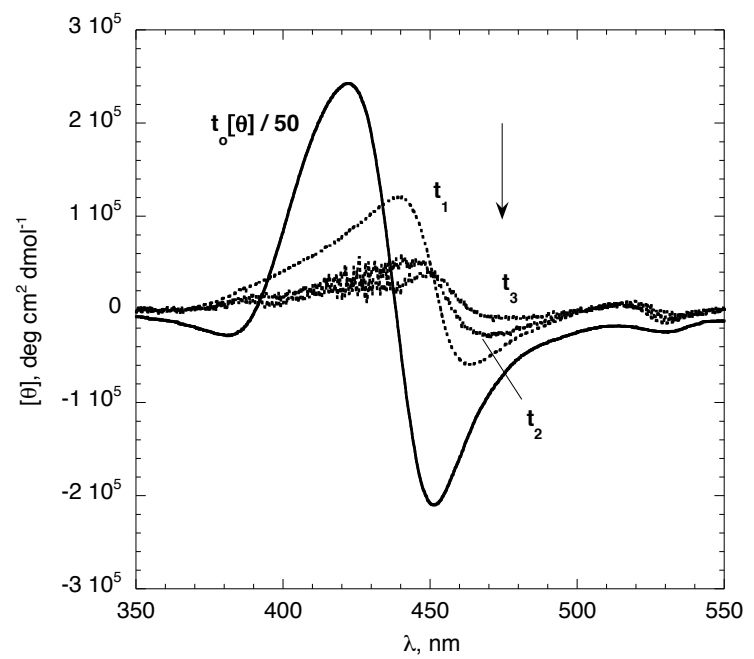

Figure S2. CD spectra evolution of the untemplated deaggregation experiment on $\mathbf{1 H}_{2}\left(7.5 \times 10^{-6} \mathrm{M} ; \mathrm{H}_{2} \mathrm{O} / \mathrm{EtOH} 75 / 25 \mathrm{v}: \mathrm{v}\right)$ by addition of $\mathbf{3} \mathbf{H}_{\mathbf{2}}\left(1.5 \times 10^{-5} \mathrm{M}\right)$. Solid line: $\mathbf{1} \mathbf{H}_{2}$ solution at $\mathrm{t}=0$ (the relative intensity has been scaled down by 50 times, for clarity); dotted lines: deaggregation $C D$ profiles at $\mathrm{t}_{1}=1 \mathrm{~s}, \mathrm{t}_{2}=3 \mathrm{~min}, \mathrm{t}_{3}=20 \mathrm{~min}$.

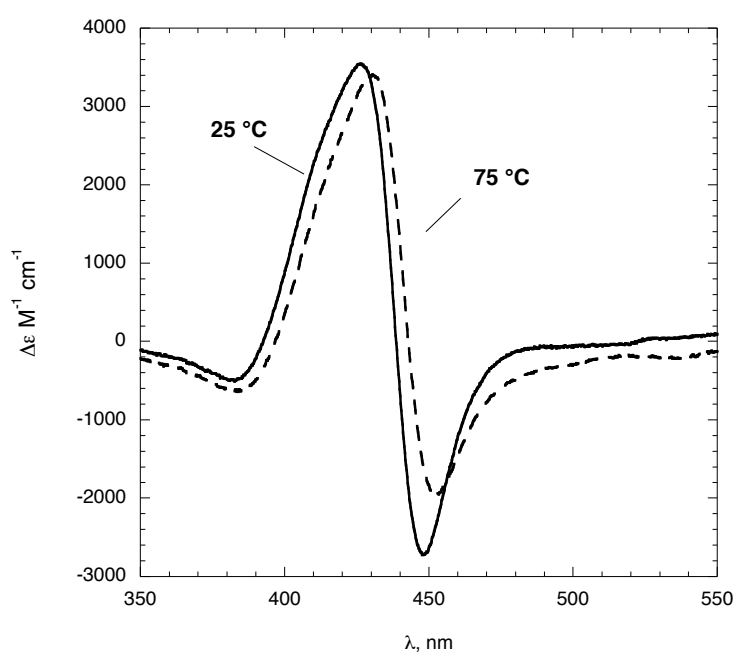

Figure S3. CD spectra evolution of the templated aggregate structure $\left(\left[\mathbf{1 H}_{\mathbf{2}}\right]=10 \mu \mathrm{M}\right.$; $\left.\left[\mathbf{2 H}_{2}\right]=5 \mu \mathrm{M} ; \mathrm{H}_{2} \mathrm{O} / \mathrm{EtOH} 75 / 25 \mathrm{v}: \mathrm{v}\right)$ with temperature. Solid line: $\mathrm{T}=25^{\circ} \mathrm{C}$; dotted lines: after heating $3 \mathrm{hr}$ at $\mathrm{T}=75^{\circ} \mathrm{C}$. 


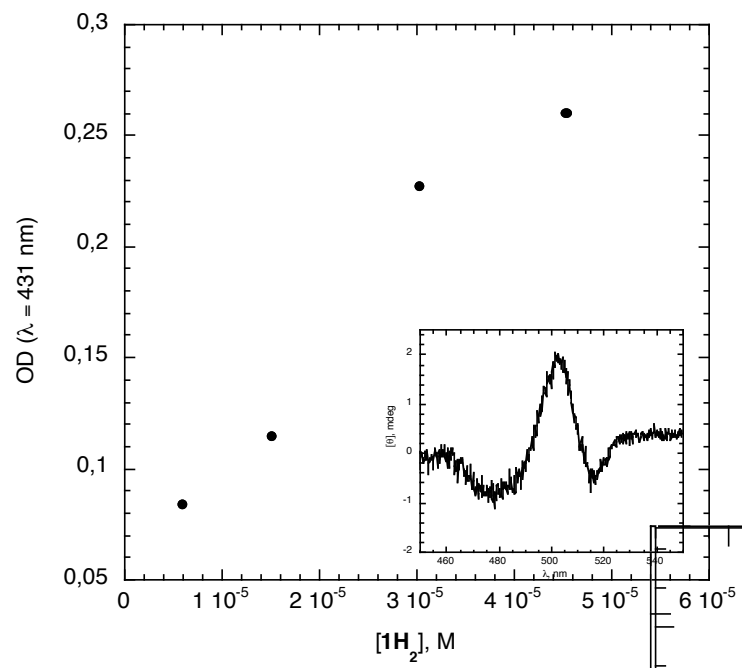

Figure S4. Dependence of glass layered porphyrin optical density $(\lambda 431 \mathrm{~nm})$ at different initial bulk concentrations. In the inset the CD spectra of porphyrin solid layer $\left(5 \times 10^{-5} \mathrm{M}\right)$ is reported. 